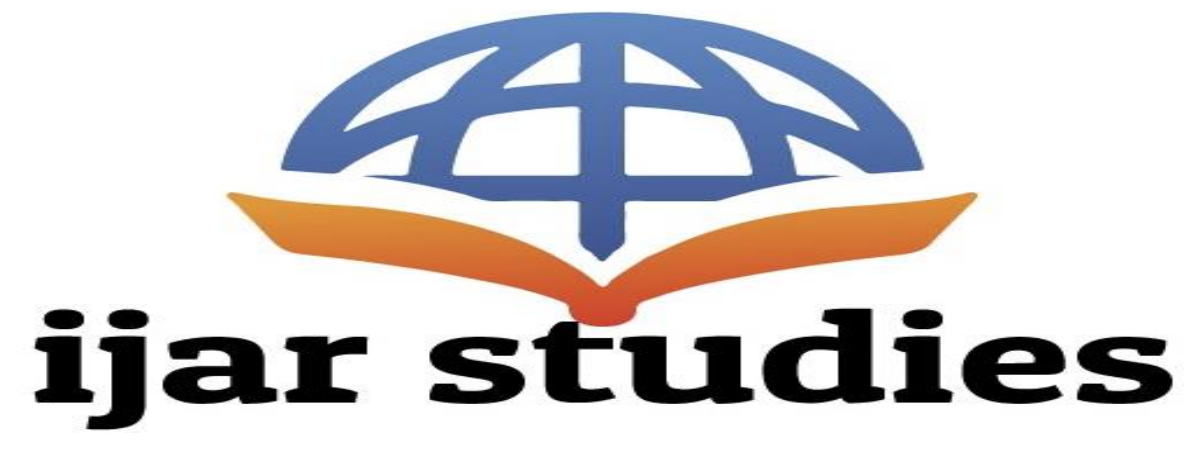

International Journal of Academic Researchs Studies Year:1, Number:1, December 2018, s.51-57

Article Arrival Date/ Yayın Geliş Tarihi 20.10.2018
The Publication Date/Yayınlanma Tarihi

23.12.2018

\title{
Yenni PATRIANI
}

Bengkulu University /Indonesia

yeyenpatrient72@gmail.com

\&

Achmad Ja'far SODİK

Bengkulu University /Indonesia

طريقة الترجمة الحرفية في فهم الكتب العربية

الملّخص

طريقة الترجمة الحرفية في فهم الكتب العربية مهمة جدا وخاصة لكثف نظام اللغتين, و تعريف الثبه والاختلاف.

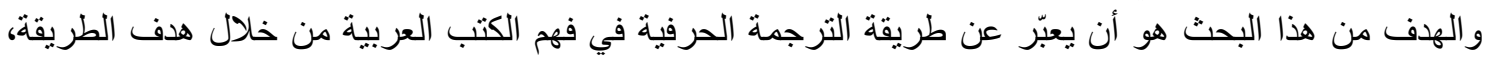

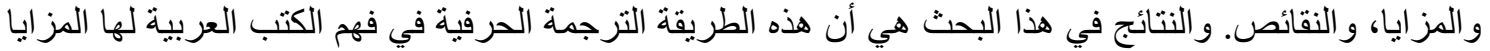

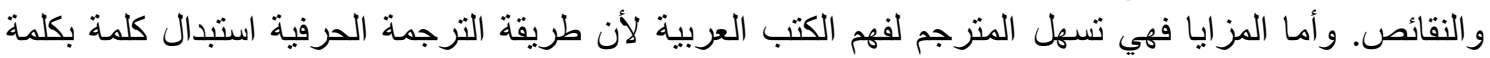

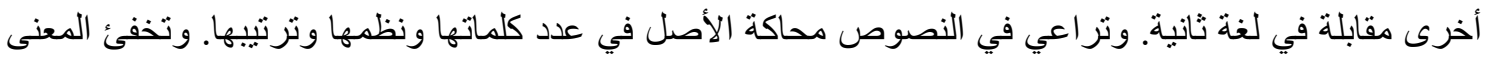

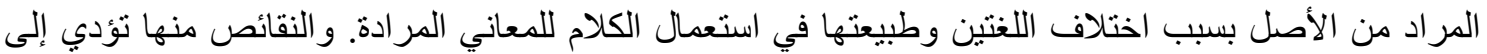

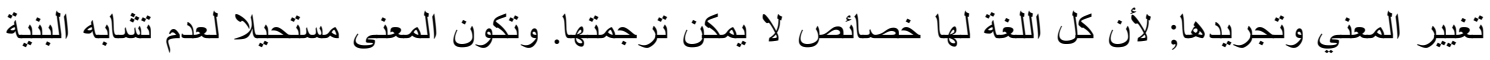
اللغوية. ونظل ناقصة وسيئة للغاية وقد تكون سبيا في تخريب اللغة ولنة افسادها. 


\begin{abstract}
Literal translation method in understanding Arabic books is very important, especially for the detection of language systems, definitions of similarities and differences. The aims of this study are to express literal translation methods in understanding Arabic books through the purpose of methods, advantages, and disadvantages. The results of this study shows that literal translation methods in understanding Arabic books have advantages and disadvantages. The advantages of this method include making easier for translators to understand Arabic books because the literal translation method replaces other words with the others in the target language, figuring out the original texts of the number of words, systems and their structures. In edition, it can hide its original meaning because of differences in language and its nature in the use of speech for the intended meaning. The disadvantage of the literal translation method is that it can cause displaces meaning of the intended word because each language has untranslatable properties. It causes difficulties in the meaning of the word in question because there is no similarity in the structures of the language. It causes damage to language because of poor in target language.
\end{abstract}

\title{
Keywords: Method, Translate, Literal, understanding, Arabic Books
}


كما كنا على سبيل المعرفة بأن الترجمة أمر هام للغاية في تبادل العلوم و المعارف والحضارة والعارة، و لا سيما

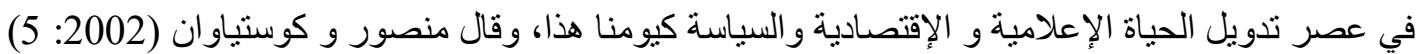

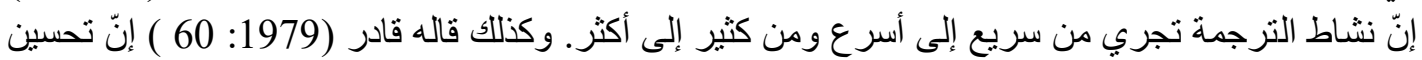

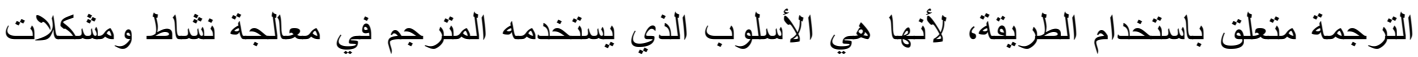

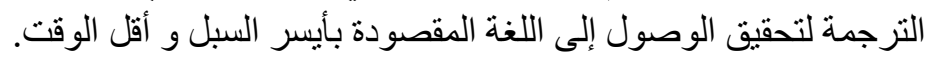

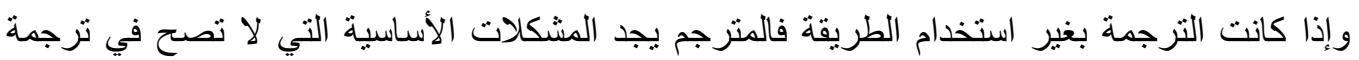

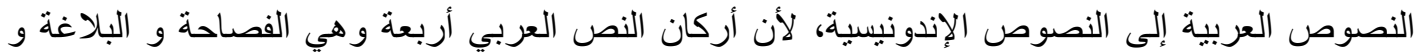

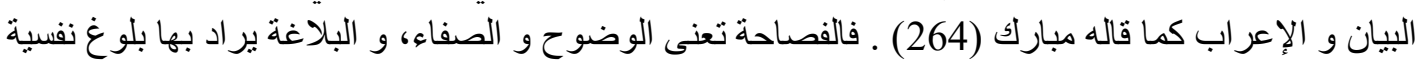

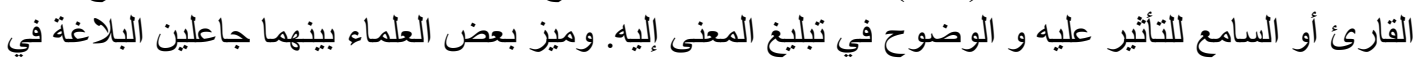

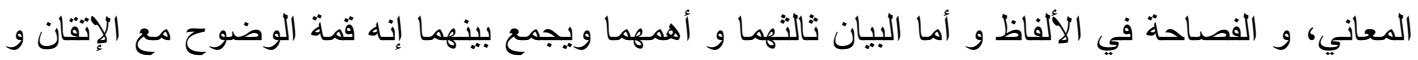
حسن استخر اج المعنى و إحكام المبنى. أما الإعر اب فيه يتضح من النص النصان القصد وتتجلى عناصر معناه بتبين الإنان

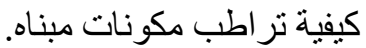

إضافة إلى ذلك، يرى الباحثان أنّ طريقة الترجمة الحرفية في فهم الكتب العربية مهمة جدا لكثنف نظام

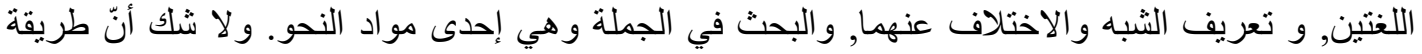

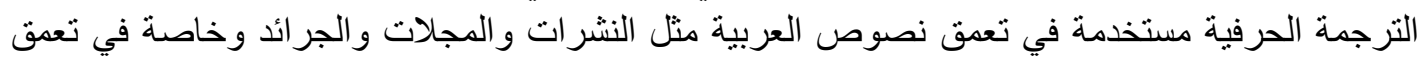
الكتب العربية لأنها من مصادر العلوم الدينية.

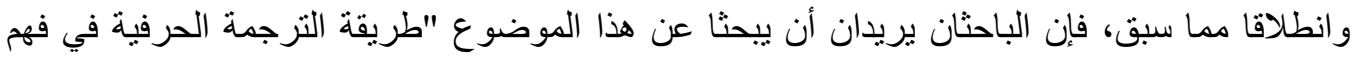

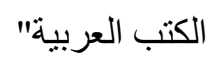

\section{مفهوم طريقة الترجمة الحرفية}

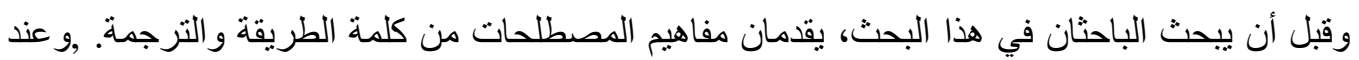

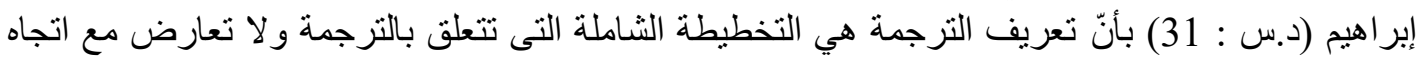

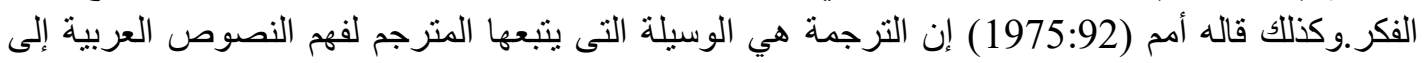

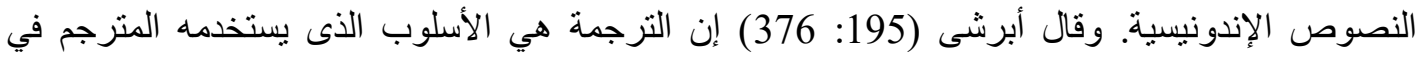

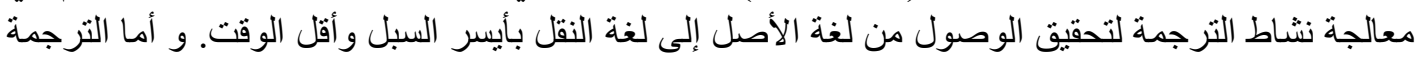

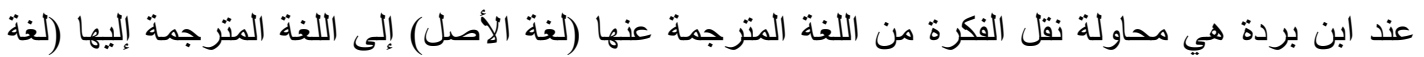
النقل). و الترجمة الحرفية عند أحمد هي استبدال كلمة بكلمة أخرى مقابلة لها لافى لغنة لغنة ثنانية.

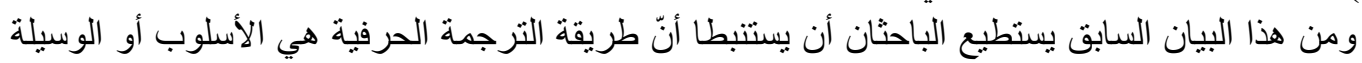

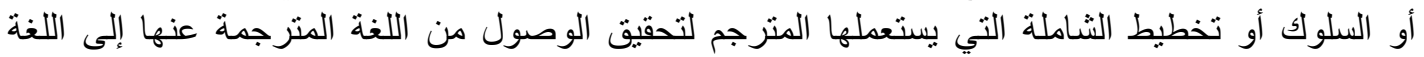
المترجمة إليها استبدال كلمة بكلمة أخرى مقابلة لها لافي لافى لغة لثنانية.

أسس الترجمة

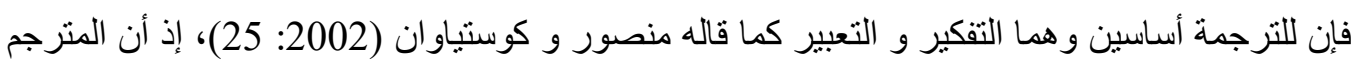

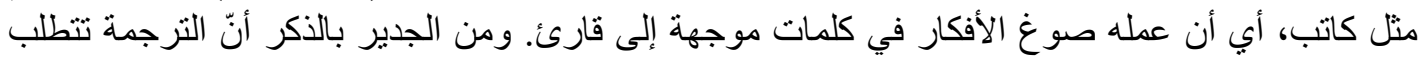

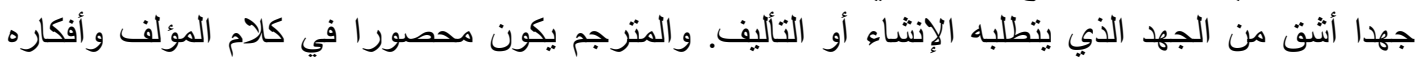
ومعانيه. لذا، فلا ننسي أن الترجمة كثير المزالق بالنسبة للمترجم الذي لم يتزود بثقافة واسعة شاملة، ومن جانب

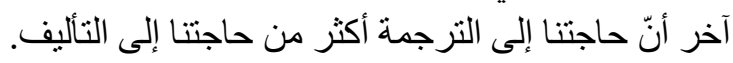


ينقسم هذه العو امل إلى أربع دلالات: دلالة معجمية، ودلالة صرفية، ودلالة نحوية، ودلالة بلاغية.

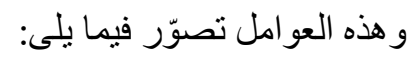

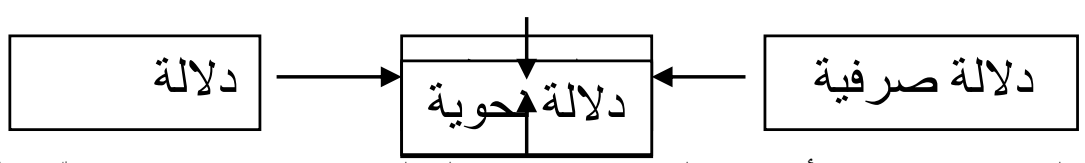

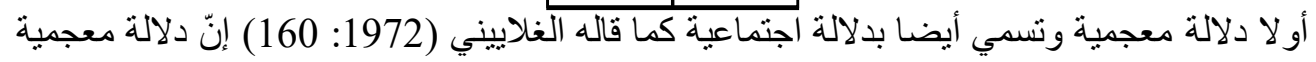

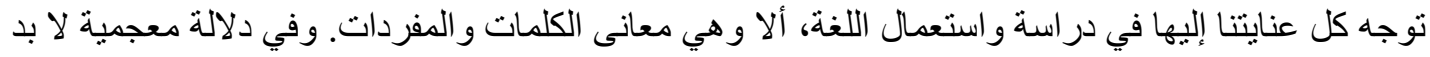

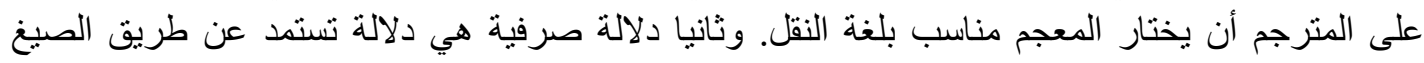

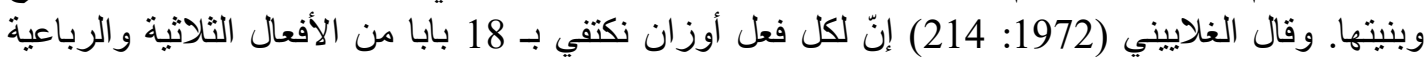

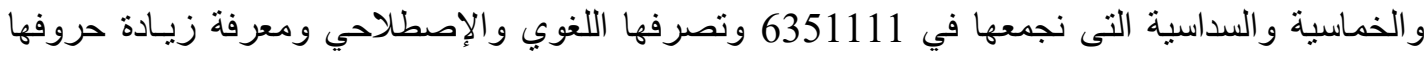

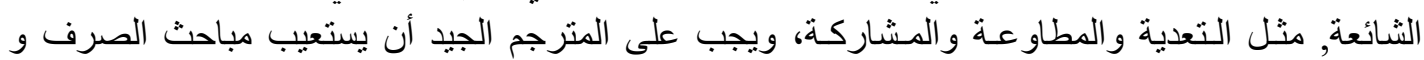

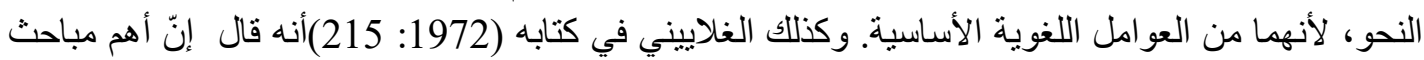

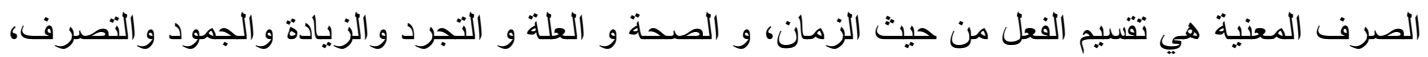

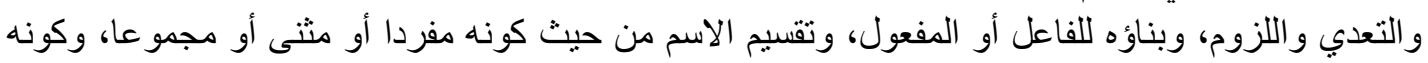

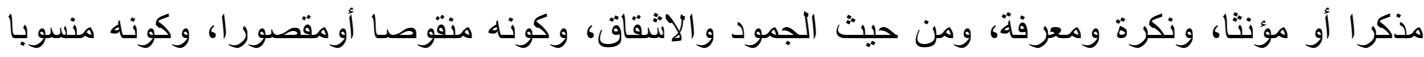

وكونه مصغر ا.

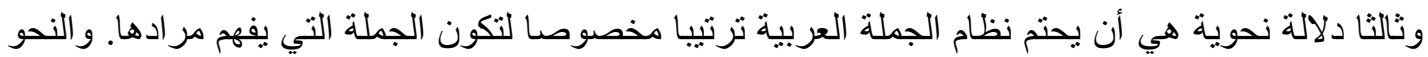

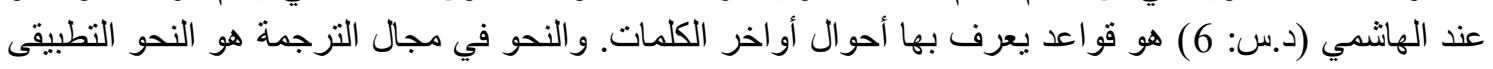

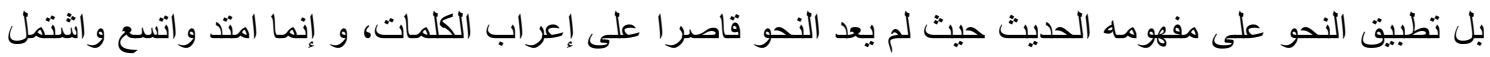

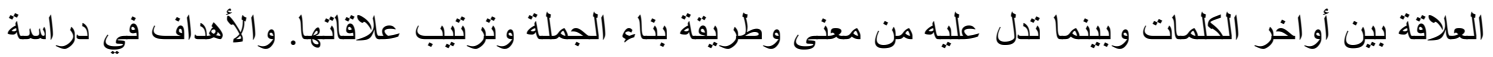

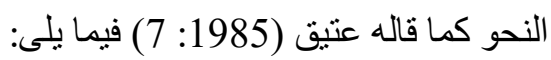

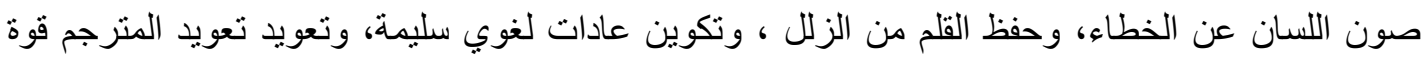

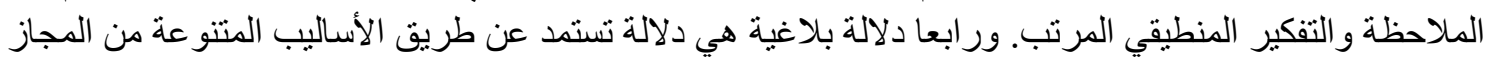

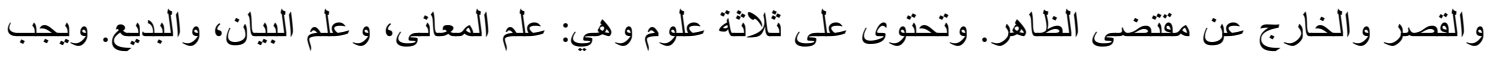

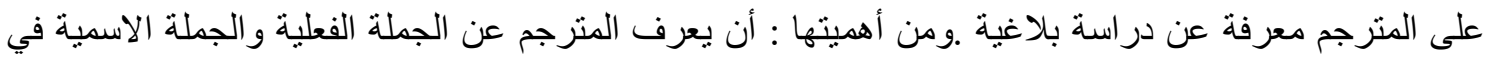

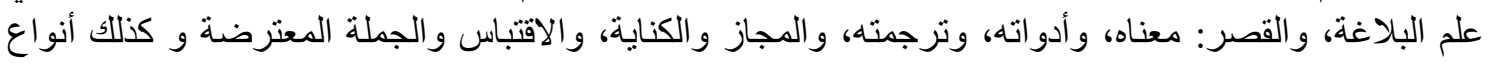

الخبر و غير ها.

أدوات الترجمة

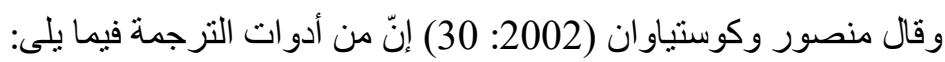

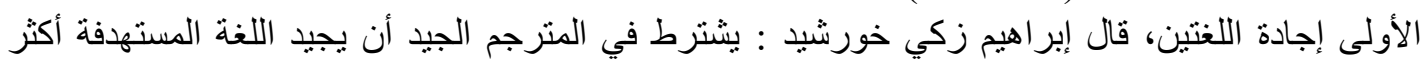

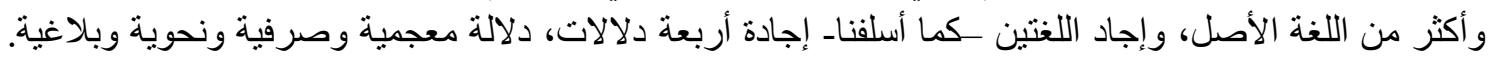

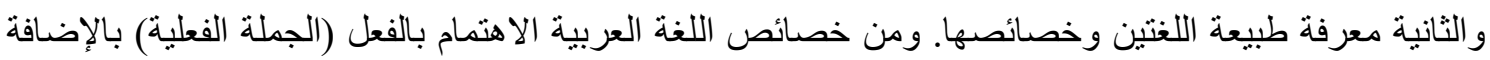

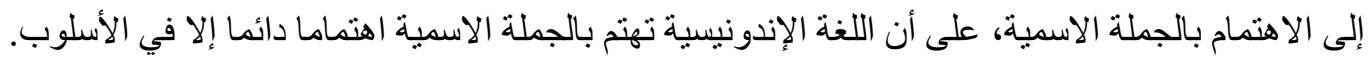

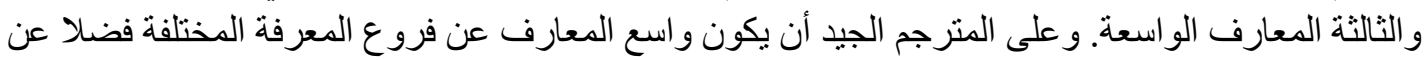

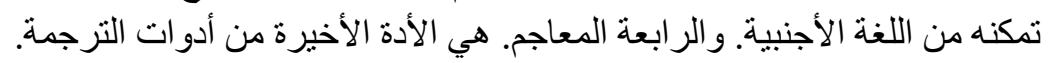
أساليب الترجمة هناك قاعدة عامة للترجمة، هي الفهم للترجمة لا الترجمة للفهم. وتتم الترجمة كما قاله منصور و كوستياوان

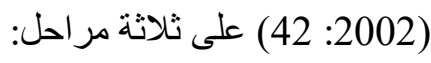


الأولى، الإمعان في قر اءة النص بصحة تحليل صيغ كلماته وتر اكيبه و أنماطه ومو اقع إعراب كلماته، ومعرفة

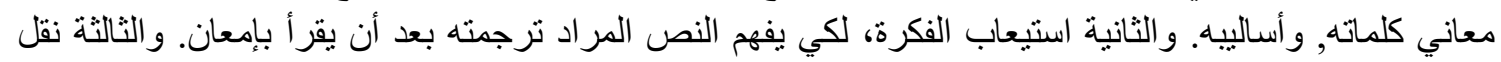
الفكرة بلغة مستهدفة سليمة وتعابير صحيحة. طريقة الترجمة الحرفية في فهم الكتب العربية

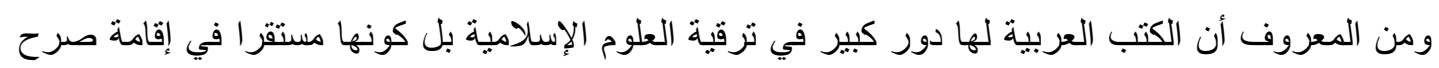

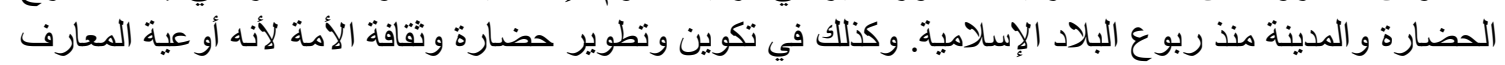

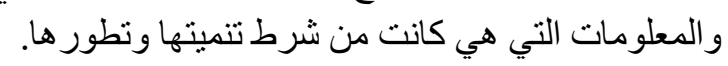

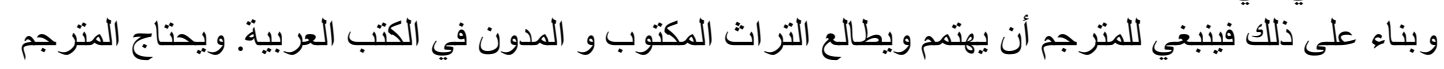

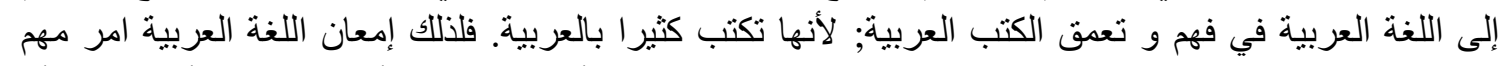

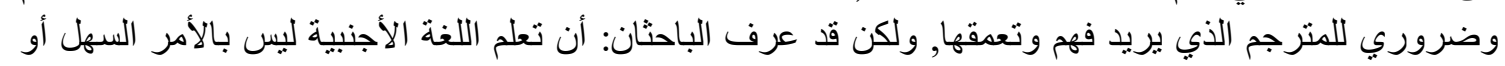

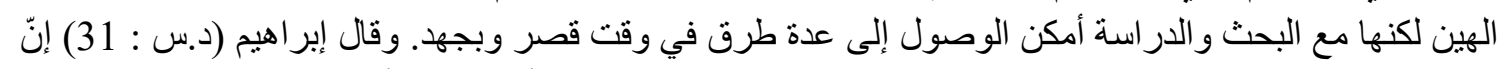

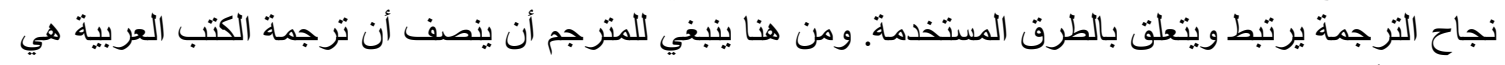

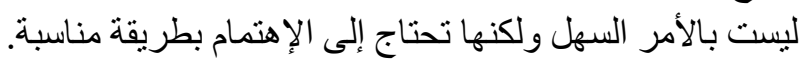

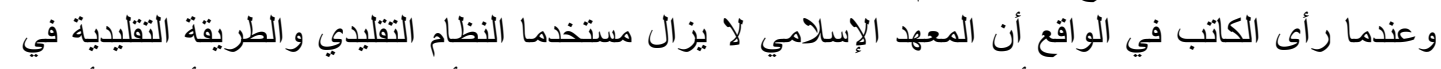

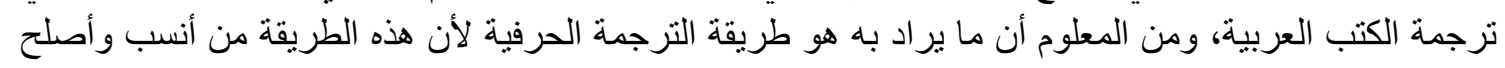
طرق الترجمة في فهم الكتب العربية. و انطلقا مما سبق فيقصد الكاتب هنا الفعالية لطريقة الترجمة الحرفية الكرفية في فهم الكتب العربية. وفي هذه الفعاليات تنقسم على مبحثين: الفعالية من ناحية أهدافها والفي الفعالية من ناحية تلفية تقويمها.

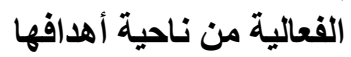

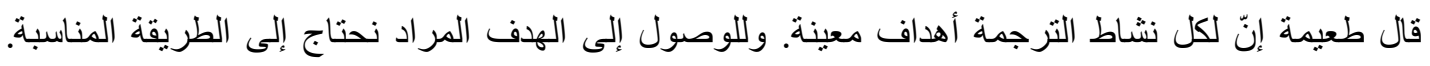

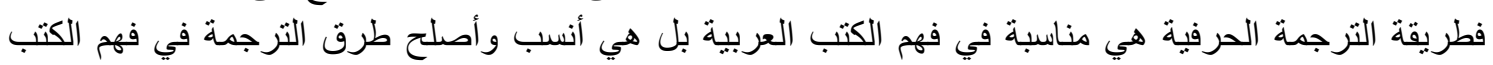

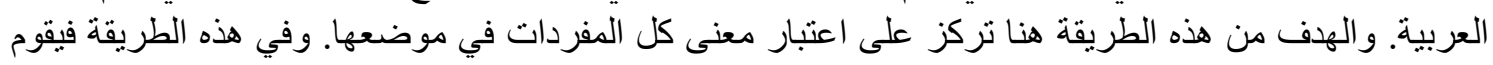

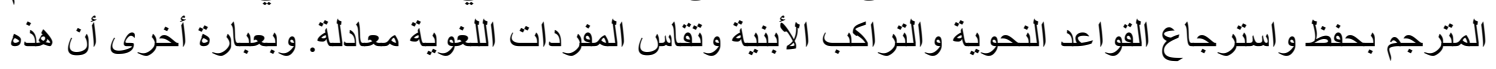

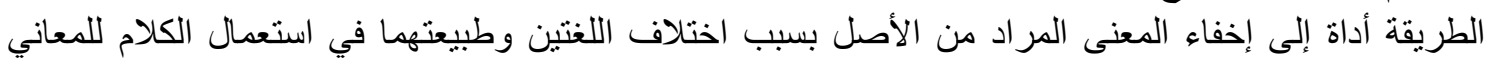
المر ادة استحسانا.

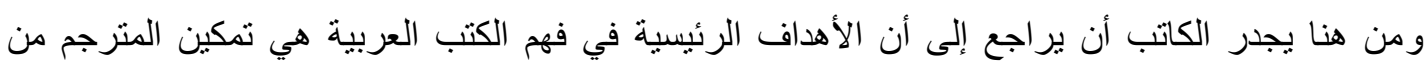

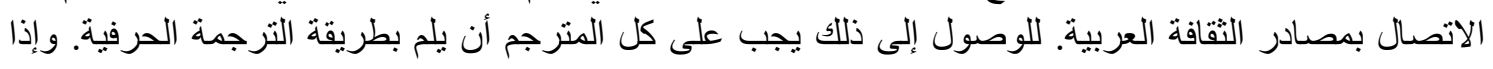

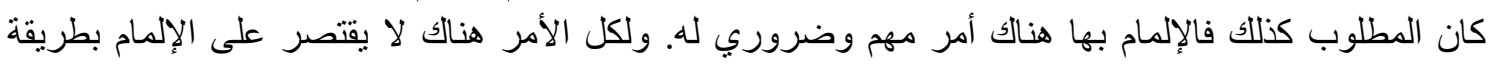

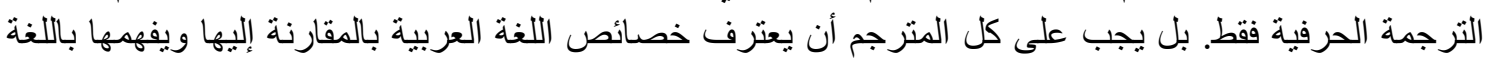

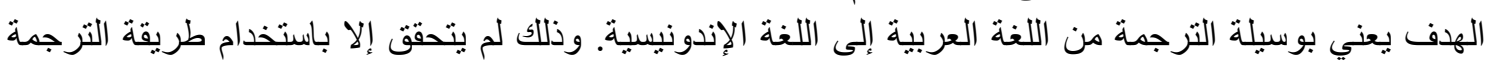

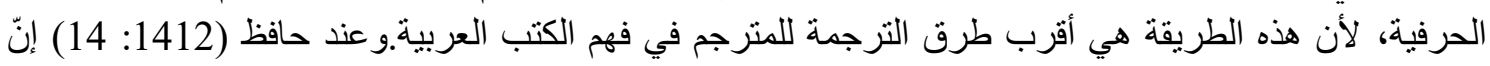

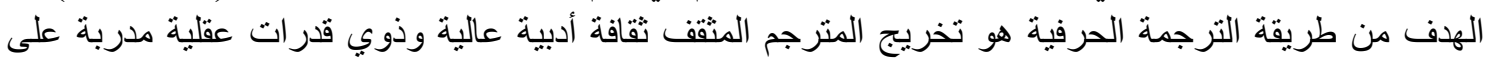

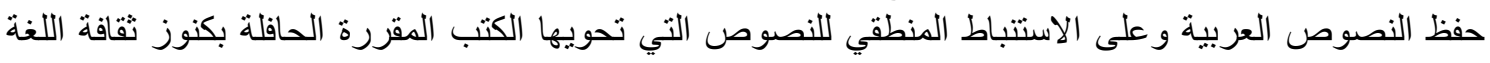

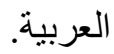

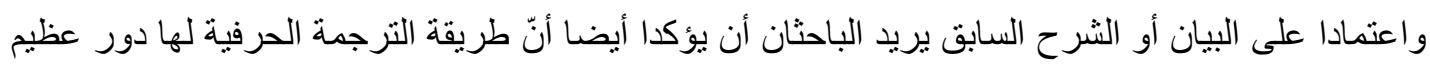

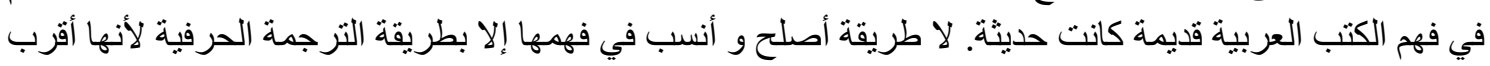
للمثرجم لتحقيق الهدف المر اد يعني لفهم الكتب العربية.

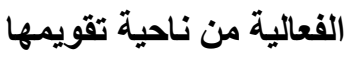

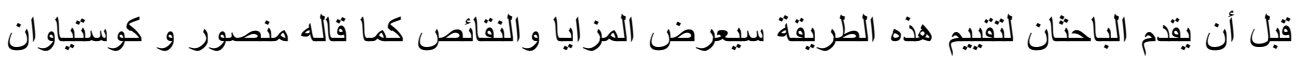

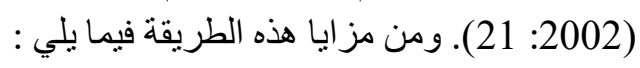




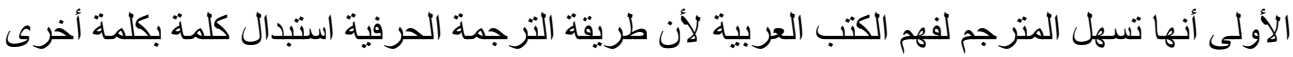

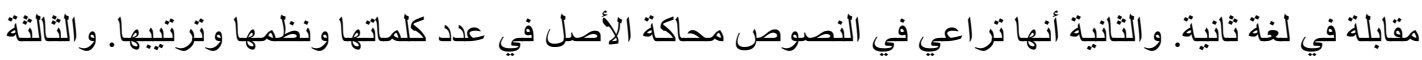
أنها تخفئ المعنى المر اد من الأصل بسبب اختلاف اللغتين وطبيعتها في استعمال الكلام للمعاني المر ادة.

$$
\text { و أما نقائص هذه الطريقة فهي كما يلي : }
$$

الأولى أنها تؤدي إلى تغيير المعني وتجريدها لأن كل اللغة لها خصائص لا يمكن ترجمنها. و الثانية

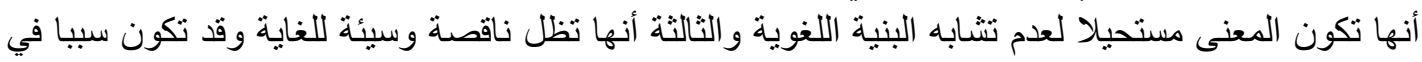

$$
\text { تخريب اللغةو وافسادها. }
$$

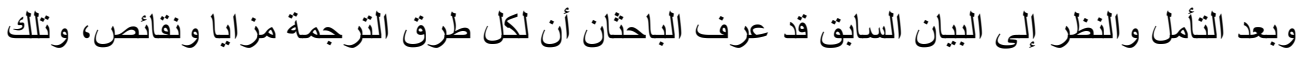

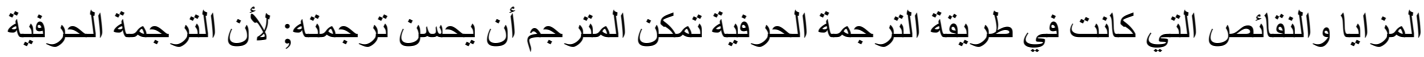
تطلق العلاجة في ضعف وصنوبته في فهم الكتب العربية.

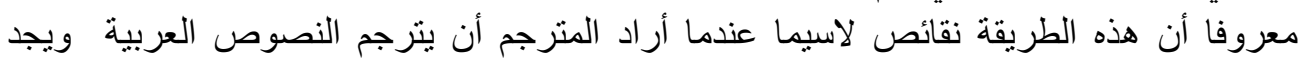

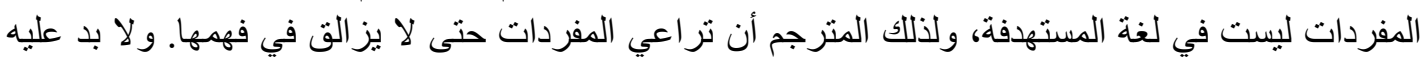

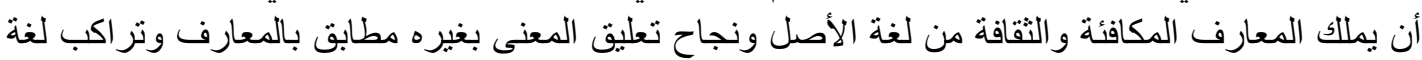
ومن جهة أخرى لابد على المترجم أن يعالج كل المشكلات في الترجمة لأن تطبيق الترجمة يحتاج

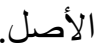

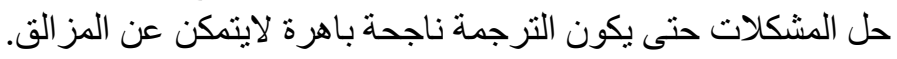

\section{الخلاصة}

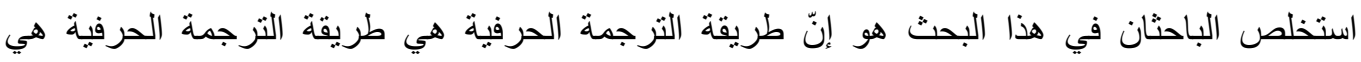
الأسلوب أو الوسيلة أو السلوك أو تخطيط الثشاملة التي يستعملها المترجم لتحقيق الوصول من اللغة التهنة المنرجمة عنها

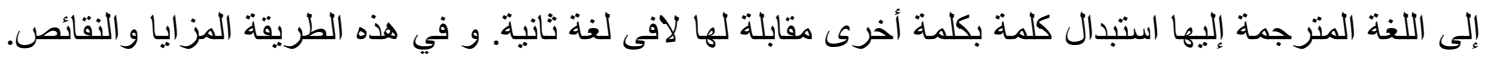

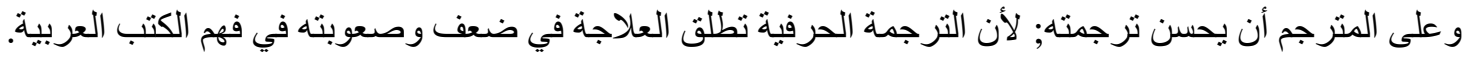




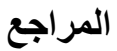

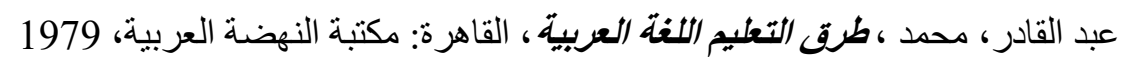

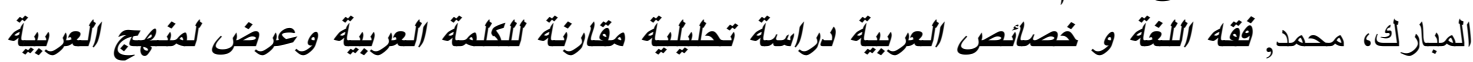

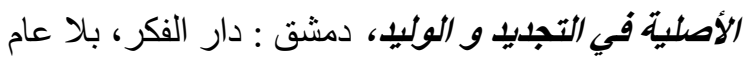

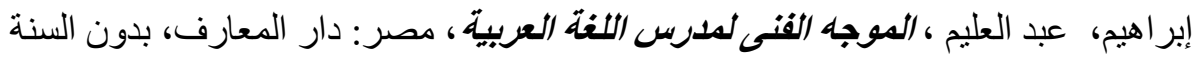

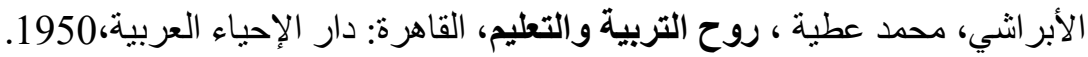

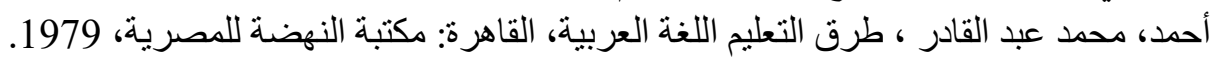

الغلاييني، مصطفى ، جامع الدروس، بيروت : المكتبة العصرية، 1972.

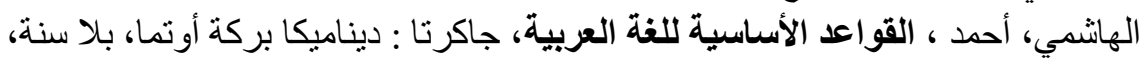

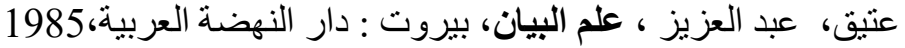

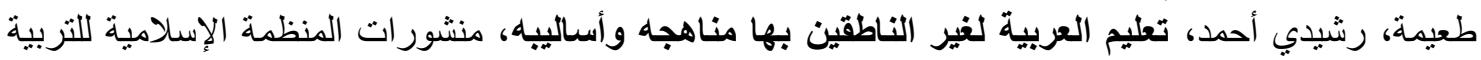

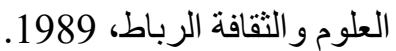

عبد الحافظ، محمود الفراج، مذكرة الدورات التربوية،، جاكرتا: جامعة الإمام محمد ابن سعود الإسلامية معهد العلوم الإسلامية والعربية في إندونيسيا، 1412.

Burdah, Ibnu, Menjadi Penerjemnah Metode Dan Wawasan Menerjemah Arab,

(Yogyakarta : Tiara Wacana,2004)

Kustiawan, Mansyur, دليل الكاتب و المترجم (Jakarta: PT Moro Segoro Agung, 2002)

Umam, Chatib, Pedoman Pengajaran Bahasa Arab Pada Perguruan Tinggi Agama/IAIN, (Jakarta: Depag RI, 1975) 